\title{
Synthesis of Ricinoleate Anion based Ionic Liquids and their Application as Green Lubricating oil Additives
}

\author{
Venkateshwarlu Kontham $^{1}$, Padmaja Korlipara ${ }^{2}$, and Madhu Devarapaga ${ }^{2}$ \\ ${ }^{1}$ Indian Institute of Chemical Technology CSIR \\ ${ }^{2}$ Affiliation not available
}

May 5, 2020

\begin{abstract}
Ricinoleate anion based ionic liquids (ILs) were synthesized from four different nitrogen containing cationic counterparts such as tetrabutylammonium, tetrapropylammonium, cetyltrimethylammonium, imidazolium and evaluated for tribological performance in two lubricant base stocks. From the tribological tests it was found that the synthesized ILs in base oil significantly reduced the wear scar diameter by $17-25 \%$ and a remarkable reduction in wear observed for all the tested load and rotation speed at optimized concentration and also improved the load carrying capacity by $25-43 \%$. The results conclude that the cation present in IL control the thermal stability, antiwear and extreme pressure properties. The imidazolium cation containing IL showed the better performance among all the ILs being studied. Additionally, the morphology of worn surface and deposition of elementals on rubbed surface lubricated with base oil and base oil containing IL was studied by scanning electron microscope (SEM) and Energy-dispersive X-ray spectroscopy (EDX). The fatty acid constituted ILs are promising immense efficiency as environmentally friendly and renewable lubricant additives since they are free from halide, sulphate and phosphate ions.
\end{abstract}

\section{Introduction}

Ionic liquids (ILs) are molten salts containing organic or inorganic cations and anions which have lower boiling point than water (Battez et al., 2016; Khan et al., 2018; Khemchandani et al., 2014; Matczak et al., 2018). Their unique features such as high thermal stability, broad liquid range, low vapour pressure and non-flammability makes ionic liquids as versatile molecules for lubrication applications (Jimeenez and Bermudez, 2008; Pensado et al., 2008; Qu et al., 2006; Somers et al., 2013; Stolte et al., 2012; Yu et al., 2008). ILs offers some distinctive advantages in reducing friction and wear between surfaces in direct contact (Ichiro, 2009; Zhou et al., 2009). The ILs composed with ammonium, phosphonium, pyrrolidinium and imidazolium cations along with tetrafluoroborate, tosylate, halide and hexafluorophosphate anions were evaluated as lubricants and their interaction with metal surfaces was studied (Minami et al., 2010; Qu et al., 2006; Somers et al., 2012; Tiago et al., 2015; Zhou et al., 2009). These studies proved that the ILs act as neat lubricants and also as additives to the basestocks. It is believed that due to their inherent polarity ILs strongly adsorb on metal surfaces to form tribochemical film, this film enhances antiwear and antifriction performance (Liu et al., 2006; Mendonca et al., 2012; Mu et al., 2008; Qu et al., 2012; Ye et al., 2001). However, there is a limitation for using ILs as neat lubricants due to their higher cost and multistep reaction procedure involved in their synthesis compared to traditional base oils (Barnhill et al., 2014; Khan et al., 2018; Zhou et al., 2014) . However, with a minimum weight percent of ILs in mineral oil and other synthetic oils performed better than the neat base oils (Amiril et al., 2017; Ma et al., 2019; Otero et al., 2014). Batteze et al. detected the film forming capacity of phosphonium cation-based ILs at low concentrations in mineral oil and also evaluated the effect of IL concentration on film forming capacity and coefficient of friction under different test conditions. The choice of changing the combination of cation and anion is possible in ILs to attain specific properties (Ma et al., 2019; Mordukhovich et al., 2013; Salih et al., 2011). Recently some of 
the ILs gained much interest as lubricant additives such as dicationic bis(ammonium) and bis(imidazolium)di[bis(salicylato)borate] ionic liquids (Gusain et al., 2014), phosphonium-alkylphosphate (Qu et al., 2015) and N,N'-dialkylimidazolium (Pejakovic et al., 2016) etc. These ILs when used as additives to lubricating oil remarkably enhanced its antiwear and antifriction properties. Zhang et al. (2017), studied the synergistic effect of polymeric IL additives with conventional additive ZDDP and found best synergism with 1:1 w/w of ZDDP and boron-containing polyisobutylene-based IL. Compared to ZDDP ILs are ash less and have stronger adsorption towards metallic surface, thus they provide better lubricity performance with low engine deposits (Mendonca et al., 2012; Oulego et al., 2018).

Currently, most of the ionic liquid based additives used for the tribological applications were synthesized with anions such as the halide [F-, Cl-, Br- or I-], phosphate and sulfate these ILs exhaust high amount of toxic components to the environment. The ILs consisting of $\left[\mathrm{PF}_{6}\right]-$ and $\left[\mathrm{BF}_{4}\right]-$ shows severe corrosion effect due to the formation of hydrofluoric acid by vigorous reaction with water (Stolte et al., 2012; Swatloski et al., 2003). Kronberger et al. (2012), investigated the eco toxicity and bio degradability of lubricant additives with pyrrolidinium and quaternary ammonium based cations combined with $\mathrm{CH}_{3} \mathrm{O}_{4} \mathrm{~S}-, \mathrm{CH}_{3} \mathrm{O}_{3} \mathrm{~S}-$ and $\left(\mathrm{CF}_{3} \mathrm{SO}_{2}\right)_{2} \mathrm{~N}$ - as counter ions. The anion $\left(\mathrm{CF}_{3} \mathrm{SO}_{2}\right)_{2} \mathrm{~N}$ - being highly resistant to biodegradation and cannot be considered for applications with potentially high environmental exposure. Conventional IL additives containing halide, sulphate and $\mathrm{PF}_{6}$ anions are replaced with environmentally benign components like fatty acids and amino acids. Biodegradable and bio compatible behaviour of amino acid and fatty acid anions are alternatives to the hazardous anions. Liwen et al. synthesized two green ILs of choline with amino acids glycene and proline, these two ILs [choline][glycine] and [choline][L-proline] significantly improved the tribological properties of base oil (Mu et al., 2015). Minami et al. (2012), stated that the both tribological and thermo-oxidative stability depend on hydrophobicity of IL anion, as the hydrophobicity of anionic part increases results in improved performance. In recent years, the fatty acid derived ILs has been explored as environmentally benign lubricating oil additives. Khatri et al. (2018), reported the synthesis of tetramethylguanidinium ionic liquids with various fatty acid anions for steel/steel contact in grade I mineral oil. Long alkyl chain constituted ILs significantly reduced the friction and wear. The present work describes the synthesis of ricinoleate anion based ILs containing various cations and evaluation of their tribological performance by blending in base oil epoxy karanja 2-ethylhexyl esters (EKE) and dioctyl sebacate (DOS). The formation of tribofilms on surface with base oil and additive was investigated by SEM and EDX analysis was used to establish the elemental composition on the worn surfaces.

\section{Experimental}

\section{Materials}

Sodium ricinoleate was purchased from TCI chemicals (Tokyo, Japan), tetra butyl ammonium bromide (TBA-Br), tetra propyl ammonium bromide (TPA-Br), cetyl trimethyl ammonium bromide (CTA-Br) and butyl hexyl imodazolium bromide (BHI-Br) were purchased from Sigma Aldrich (St. Louis, USA). Highest grade purity of solvents were purchased from SD Fine Chemicals (Mumbai, India).

\section{Characterization}

The synthesized ionic liquids were characterized by ${ }^{1} \mathrm{H}$ and ${ }^{13} \mathrm{C}$ NMR spectra on Varian 300 and $75 \mathrm{MHz}$, respectively using trimethylsilane (TMS) as internal standard. IR spectra were recorded on Perkin-Elmer Fourier transform (FT-IR) spectrum in chloroform solvent.

\section{Synthetic Procedure}

Ricinoleate anion-based ionic liquids having four variable nitrogen containing cations were synthesized by a facile metathesis reaction as per the earlier reported procedure (Gusain et al., 2016). The reaction proceeds in a single step by stirring equimolar ratio of both bromide salt and sodium ricinoleate in water for $18 \mathrm{~h}$. The reaction mixture was extracted by using dichloromethane (DCM) followed by washing with distilled water to remove excess sodium ricinoleate and sodium bromide. The solvent was removed under reduced pressure and the obtained ionic liquids were dried for $48 \mathrm{~h}$ at $80{ }^{\circ} \mathrm{C}$. The synthesized four ionic liquids tetra- 
butylammonium (Z)-12-hydroxyoctadec-9-enoate (TBA-RA), tetrapropylammonium (Z)-12-hydroxyoctadec9-enoate (TPA-RA), N,N,N-trimethylhexadecan-1-aminium (Z)-12-hydroxyoctadec-9-enoate (CTB-RA), 1butyl-3-hexyl-1H-imidazol-3-ium (Z)-12-hydroxyoctadec-9-enoate (BHI-RA) were characterised by NMR and FT-IR.

Synthesis of Tetrabutylammonium (Z)-12-Hydroxyoctadec-9-enoate (TBA-RA)

Quantities of substrates taken: Sodium ricinoelate (1g, $0.0031 \mathrm{~mol})$, TBA-Br (1g, $0.0031 \mathrm{~mol})$, yield obtained $90 \%$ (1.46 g). ${ }^{1} \mathrm{H}$ NMR $\left(\mathrm{CDCl}_{3}, \mathrm{ppm}\right): \delta 5.55$ (m, - $\left.\mathrm{CH}=\mathrm{CH}-\right), 5.38$ (m, - $\left.\mathrm{CH}=\mathrm{CH}-\right), 3.61$ (m, $\left.1 \mathrm{H},-\mathrm{CHOH}\right)$, $3.31\left(\mathrm{~m}, 8 \mathrm{H},-\mathrm{CH}_{2} \mathrm{~N}\right), 2.26\left(\mathrm{t}, 2 \mathrm{H},-\mathrm{H}_{2} \mathrm{CCOO}\right), 2.18\left(\mathrm{t}, 2 \mathrm{H},-\mathrm{CH}_{2}-\mathrm{C}=\mathrm{C}-\right), 2.04\left(\mathrm{t}, 2 \mathrm{H},-\mathrm{CH}_{2}-\mathrm{C}=\mathrm{C}-\right), 1.65(\mathrm{~m}$, $\left.8 \mathrm{H}, 4 \mathrm{xCH}_{2}\right), 1.58\left(\mathrm{~m}, 2 \mathrm{H},-\mathrm{CH}_{2}\right), 1.43\left(\mathrm{~m}, 2 \mathrm{H},-\mathrm{CH}_{2}\right), 1.33\left(\mathrm{~m}, 12 \mathrm{H}, 6 \mathrm{xCH}_{2}\right), 1.28\left(\mathrm{~m}, 12 \mathrm{H}, 6 \mathrm{x}-\mathrm{CH}_{2}\right), 1.01$ $\left(\mathrm{m}, 12 \mathrm{H}, 4 \mathrm{x}-\mathrm{CH}_{3}\right), 0.88\left(\mathrm{t}, 3 \mathrm{H}, \mathrm{CH}_{3}\right) .{ }^{13} \mathrm{C} \mathrm{NMR}\left(\mathrm{CDCl}_{3}, \mathrm{ppm}\right): \delta 178.8,133.2,124.9,71.3,58.8,36.6,35.8$, 31.7, 29.7, 25.5, 22.7, 19.6, 13.8. IR $\left(\mathrm{CHCl}_{3}, \mathrm{~cm}^{-1}\right)$ : 3330, 3004, 2929, 2867, 1713, 1571, 1470, 1248, 749.

Synthesis of Tetrapropylammonium (Z)-12-Hydroxyoctadec-9-enoate (TPA-RA)

Quantities of substrates taken: Sodium ricinoelate $(1 \mathrm{~g}, 0.0031 \mathrm{~mol})$, TPA-Br (1g, $0.0037 \mathrm{~mol})$, yield obtained $86 \%(1.24 \mathrm{~g}) .{ }^{1} \mathrm{H}$ NMR $\left(\mathrm{CDCl}_{3}, \mathrm{ppm}\right): \delta 5.54$ (m, - $\left.\mathrm{CH}=\mathrm{CH}-\right), 5.38$ (m, - $\left.\mathrm{CH}=\mathrm{CH}-\right), 3.60(\mathrm{~m}, 1 \mathrm{H},-\mathrm{CHOH})$, $3.27\left(\mathrm{~m}, 8 \mathrm{H},-\mathrm{CH}_{2} \mathrm{~N}\right), 2.20\left(\mathrm{t}, 2 \mathrm{H},-\mathrm{H}_{2} \mathrm{CCOO}\right), 2.19\left(\mathrm{t}, 2 \mathrm{H},-\mathrm{CH}_{2}-\mathrm{C}=\mathrm{C}-\right), 2.02\left(\mathrm{t}, 2 \mathrm{H},-\mathrm{CH}_{2}-\mathrm{C}=\mathrm{C}-\right), 1.73(\mathrm{~m}$, $\left.8 \mathrm{H}, 4 \mathrm{xCH}_{2}\right), 1.56\left(\mathrm{~m}, 2 \mathrm{H},-\mathrm{CH}_{2}\right), 1.44\left(\mathrm{~m}, 2 \mathrm{H},-\mathrm{CH}_{2}\right), 1.33\left(\mathrm{~m}, 4 \mathrm{H}, 2 \mathrm{xCH}_{2}\right), 1.27\left(\mathrm{~m}, 12 \mathrm{H}, 6 \mathrm{x}-\mathrm{CH}_{2}\right), 1.03$

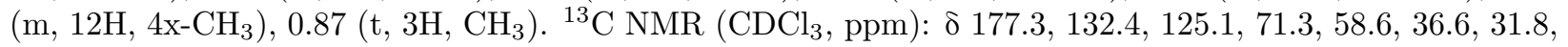
35.2, 29.6, 25.5, 22.7, 15.7, 14.1, 13.5. IR $\left(\mathrm{CHCl}_{3}, \mathrm{~cm}^{-1}\right): 3346,3005,2922,2854,1709,1554,1451,1151$, 731.

Synthesis of N,N,N-Trimethylhexadecan-1-aminium (Z)-12-Hydroxyoctadec-9-enoate (CTB-RA)

Quantities of substrates taken: Sodium ricinoelate (1g, $0.0031 \mathrm{~mol}), \mathrm{CTA}-\mathrm{Br}(1 \mathrm{~g}, 0.0027 \mathrm{~mol})$, yield obtained $88 \%$ (1.54 g). ${ }^{1} \mathrm{H}$ NMR $\left(\mathrm{CDCl}_{3}, \mathrm{ppm}\right): \delta 5.53(\mathrm{~m},-\mathrm{CH}=\mathrm{CH}-), 5.37$ (m, -CH=CH-), $3.60(\mathrm{~m}, 1 \mathrm{H},-\mathrm{CHOH})$, $3.39\left(\mathrm{t}, 2 \mathrm{H},-\mathrm{CH}_{2} \mathrm{~N}\right), 3.32\left(\mathrm{~s}, 9 \mathrm{H},-\mathrm{CH}_{3}\right), 2.48\left(\mathrm{t}, 2 \mathrm{H},-\mathrm{H}_{2} \mathrm{CCOO}\right), 2.15\left(\mathrm{~m}, 2 \mathrm{H},-\mathrm{CH}_{2}-\mathrm{C}=\mathrm{C}-\right), 2.02(\mathrm{t}, 2 \mathrm{H}$, $\left.-\mathrm{CH}_{2}-\mathrm{C}=\mathrm{C}-\right), 1.72\left(\mathrm{~m}, 8 \mathrm{H}, 4 \mathrm{xCH}_{2}\right), 1.55\left(\mathrm{~m}, 2 \mathrm{H},-\mathrm{CH}_{2}\right), 1.44\left(\mathrm{~m}, 2 \mathrm{H},-\mathrm{CH}_{2}\right), 1.34\left(\mathrm{~m}, 4 \mathrm{H}, 2 \mathrm{xCH}_{2}\right), 1.26(\mathrm{~m}$, $\left.36 \mathrm{H}, 18 \mathrm{x}-\mathrm{CH}_{2}\right), 0.88\left(\mathrm{t}, 3 \mathrm{H},-\mathrm{CH}_{3}\right){ }^{13} \mathrm{C} \mathrm{NMR}\left(\mathrm{CDCl}_{3}, \mathrm{ppm}\right): \delta 180.4,133.0,125.5,71.2,66.9,53.4,37.6$, 35.6, 31.8, 29.7, 25.1, 22.5, 14.1. IR $\left(\mathrm{CHCl}_{3}, \mathrm{~cm}^{-1}\right)$ : 3356, 3008, 2924, 2853, 1760, 1556, 1463, 1218, 773.

Synthesis of 1-Butyl-3-hexyl-1H-Imidazol-3-ium (Z)-12-Hydroxyoctadec-9-enoate (BHI-RA)

Quantities of substrates taken: Sodium ricinoelate (1g, $0.0031 \mathrm{~mol})$, BHI-Br (1g, $0.0034 \mathrm{~mol})$, yield obtained $84 \%(1.28 \mathrm{~g}) .{ }^{1} \mathrm{H}$ NMR $\left(\mathrm{CDCl}_{3}, \mathrm{ppm}\right): \delta 7.28(\mathrm{~s}, 1 \mathrm{H}), 7.18(\mathrm{~d}, 2 \mathrm{H}), 5.52(\mathrm{~m},-\mathrm{CH}=\mathrm{CH}-), 5.40(\mathrm{~m},-\mathrm{CH}=\mathrm{CH}-)$, $5.31\left(\mathrm{t}, 2 \mathrm{H},-\mathrm{CH}_{2} \mathrm{~N}^{+}\right), 4.34\left(\mathrm{t}, 2 \mathrm{H},-\mathrm{CH}_{2} \mathrm{~N}\right), 3.59(\mathrm{~m}, 1 \mathrm{H},-\mathrm{CHOH}), 2.38\left(\mathrm{t}, 2 \mathrm{H},-\mathrm{H}_{2} \mathrm{CCOO}\right), 2.21(\mathrm{~m}, 4 \mathrm{H}$, $\left.-\mathrm{CH}_{2}-\mathrm{C}=\mathrm{C}-\right), 2.01\left(\mathrm{~m}, 4 \mathrm{H}, 4 \mathrm{x}-\mathrm{CH}_{2}\right), 1.57\left(\mathrm{~m}, 2 \mathrm{H},-\mathrm{CH}_{2}\right), 1.40\left(\mathrm{~m}, 2 \mathrm{H},-\mathrm{CH}_{2}\right), 1.30\left(\mathrm{~m}, 4 \mathrm{H}, 2 \mathrm{xCH}_{2}\right), 1.26$ $\left(\mathrm{m}, 18 \mathrm{H}, 9 \mathrm{xCH}_{2}\right), 1.0\left(\mathrm{~m}, 8 \mathrm{H}, 4 \mathrm{x}-\mathrm{CH}_{2}\right), 0.88\left(\mathrm{t}, 3 \mathrm{H}, \mathrm{CH}_{3}\right) \cdot{ }^{13} \mathrm{C} \mathrm{NMR}\left(\mathrm{CDCl}_{3}, \mathrm{ppm}\right): \delta 180.1,138.2,133.1$, $125.9,121.4,71.5,53.4,49.3,37.8,31.8,29.9,25.5,22.7,13.8,13.4$. IR $\left(\mathrm{CHCl}_{3}, \mathrm{~cm}^{-1}\right): 3355,3136,3003$, $2957,2856,1760,1698,1557,1463,1215,755$.

\section{Tribological Tests}

Synthesized ionic liquids were analyzed for their tribological performance using four-ball tribotester (Stanhope-Seta, UK) by blending with base fluid varying concentration from 0.2 to $1.2 \mathrm{wt} \%$. The antiwear behaviour was examined as per the method ASTM D 4172 at $40 \mathrm{~kg}$ load and $1200 \mathrm{rpm}$ for $60 \mathrm{~min}$ at $60-70{ }^{\circ} \mathrm{C}$ at different additive concentrations. At the end of each test, the lower three balls were washed with hexane and ether and air dried for $15 \mathrm{~min}$. The scar on balls was measured with Mitutoyo toolmaker's microscope and the average of three measurements was taken as mean wear scar diameter (MWD). The load carrying capacity of ionic liquids blended base oil was analyzed as per the method IP 239 at $1475 \mathrm{rpm}$ and time duration $60 \mathrm{sec}$. The analysis was carried out twice and the average of two values was reported.

\section{Surface Characterization}


Carl Zeiss (model no EVO18, Germany) scanning electron microscope (SEM) was used to study the morphology of worn surface lubricated with base oil and base oil containing ionic liquid. The elemental composition on worn surface was identified by energy dispersive X-ray spectroscopy (EDS) attached with SEM.

\section{Thermal Properties}

Differential scanning calorimeter (DSC) was used to measure the thermal properties such as melting and crystallization temperatures of synthesized ionic liquids (DSC Q-100 thermal analyzer from TA instruments). Typically, $5 \pm 0.5 \mathrm{mg}$ of tested sample was weighed in sealed aluminum pan and placed in the equipment chamber and maintaining continuous nitrogen flow at $50 \mathrm{~mL} / \mathrm{min}$. Both the heating and cooling cycles were performed at -100 to $100{ }^{\circ} \mathrm{C}$ at the heating rate of $5{ }^{\circ} \mathrm{C} / \mathrm{min}$. The melting and crystallization temperatures were determined by calculating the integrated area of concerned peaks. Thermal degradation temperature of ionic liquids was determined by thermo gravimetric analysis (TGA) using TA Q500 (TA Instruments, Inc., New Castle, DE, USA). Typically, 4-5 mg of sample was placed in $\alpha-\mathrm{Al}_{2} \mathrm{O}_{3}$ crucible under continues nitrogen flow of $60 \mathrm{~mL}$ per min at the heating rate of $10^{\circ} \mathrm{C} / \mathrm{min}$ from room temperature to $500{ }^{\circ} \mathrm{C}$.

\section{Results and Discussion}

\section{Synthesis and Characterization}

Ricinoleic acid $((9 \mathrm{Z}, 12 \mathrm{R})$-12-hydroxy-9-octadecenoic acid) is the most abundant fatty acid in castor oil and it provides better lubricity performance due to the presence of hydroxy functionality (Drown et al., 2009; Madankar et al., 2013). Four ricinoleate anion based ILs with different types of bromine salts (TBA-Br, TPA-Br, CTB-Br and BHI-Br) were synthesized using a green synthetic route and the chemical structures of synthesized ILs is given in Fig. 1. The synthesized ricinoleate anion-based ILs were characterised by ${ }^{1} \mathrm{H},{ }^{13} \mathrm{C}$ NMR and FTIR spectroscopy. The characteristic peak appeared at $3330-3356 \mathrm{~cm}^{-1}$ in the FTIR spectrum (Fig. 2) is due to hydroxy functional group. The signals observed at $3008-3004 \mathrm{~cm}^{-1}$ are due to unsaturation and the peaks appeared in the range of $1713-1698 \mathrm{~cm}^{-1}$ and $1470-1451 \mathrm{~cm}^{-1}$ correspond to $\mathrm{C}=\mathrm{O}, \mathrm{COO}$ stretching vibrations respectively which confirm the presence of carboxylate group. Strong vibrational bands appeared at 2929-2854 $\mathrm{cm}^{-1}$ corresponding to asymmetric and symmetric $\mathrm{C}-\mathrm{H}$ frequencies of the alkyl chain. The peaks present at $1470-1386 \mathrm{~cm}^{-1}$ are attributed to the methylene and methyl bending modes in the cationic alkyl chains.

The peaks observed at $0.87-0.88 \mathrm{ppm}$ in ${ }^{1} \mathrm{H}$ NMR spectra are ascribed to terminal methyl protons of fatty acid anion and the corresponding carbons in the ${ }^{13} \mathrm{C}$ NMR spectra given signals at 13.4-14.1 ppm. The methylene groups in long alkyl chain of fatty acid anion exhibited proton and carbon peaks in the range of 1.26-1.73 and 15.7-31.8 ppm respectively. The methylene protons adjacent to the electronegative carboxylic group (COO-) showed downfield signals near 2.20-2.48 ppm as triplet peak. Moreover, the signals observed at 178.8-183.3 ppm and 35.8-37.8 ppm in ${ }^{13} \mathrm{C}$ spectra are due to the $\mathrm{COO}$ - and neighbouring $\mathrm{CH}_{2}$ carbons respectively. The unsaturated protons and the protons adjacent to unsaturation shows chemical shifts at 5.36-5.55, 2.01-2.21 ppm and their carbon signals appeared at 124.9-125.9 and 29.6-29.9 ppm respectively. The more prominent peaks appeared at 7.18-7.28 ppm and $121 \mathrm{ppm}$ in ${ }^{1} \mathrm{H}$ and ${ }^{13} \mathrm{C}$ spectra indicate the presence of aromatic protons and carbons for BHI-RA ionic liquid. The protons adjacent to the cationic centred nitrogen suffer from severe deshielding effect, these proton signals appeared at 3.27-3.39 ppm. Further moving away from the nitrogen centre the chemical shift values shifted to upfield (Gusain et al., 2016).

\section{Thermal Properties}

Thermal properties such as melting and crystallisation behaviour during the phase transition of the synthesized ionic liquids were determined by DSC thermo grams. The results obtained from the test is summarised in Fig. 3 and Table 1. Fig. 3 shows the DSC patterns of ionic liquids CTB-RA and BHI-RA. The CTB-RA exhibits the melting point at $2.6 \mathrm{degC}$ during the heating cycle and crystallises at $-7.8 \operatorname{deg} \mathrm{C}$ during the cooling cycle. Table 1 summarises the $\mathrm{T}_{\mathrm{m}}$ and $\mathrm{T}_{\mathrm{c}}$ temperatures of fatty acid based IL's. It is indicating that the significant differences in their $T_{m}$ and $T_{c}$ were observed. The difference in their $T_{m}$ and $T_{c}$ might be due to the difference in their cationic structure. Imidazolium cation containing IL showed lower $\mathrm{T}_{\mathrm{m}}$ and $\mathrm{T}_{\mathrm{c}}$ tem- 
peratures than all the quaternary ammonium salts. This is ascribed to the lower Vander Walls interaction of imidazolium cation due to sterically hindered structure. McFarlane et al ., stated that alkyl-imidazolium ions the geometric packing constrained the planar imidazolium ring, moreover, it has dangling alkyl chains, combined with the delocalization of the charge over the $\mathrm{N}-\mathrm{C}-\mathrm{N}$ moiety in the ring, with all of them serving to decrease the ion-ion interactions and lower the melting point (McFarlane et al., 2000). The higher $\mathrm{T}_{\mathrm{m}}$ and $\mathrm{T}_{\mathrm{c}}$ observed for CTB-RA is due to the high Vander Walls interaction between the methylene groups, as increasing the number of methylene groups increases Vander Walls interaction which leads to higher $\mathrm{T}_{\mathrm{m}}$ and $\mathrm{T}_{\mathrm{c}}$.

Thermogravimetric analysis was carried out to find the thermal decomposition stability of synthesized ILs by determining the weight loss temperature. Fig. 4 shows the thermal decomposition patterns of the ILs under the nitrogen atmosphere. Thermal stability was measured in terms of onset decomposition temperature $\left(\mathrm{T}_{\mathrm{d} \text { (onset) }}\right)$ and maximum weight loss temperature $\left(\mathrm{T}_{\mathrm{d}(\max )}\right)$. The fatty acid chain length has significant effect on the thermal degradation temperature of ILs. Exclusively, the longer chain fatty acid anion containing ILs decomposed at higher temperature due to increasing Vander Waals interaction (Gusain and Khatri, 2016). All the synthesized ILs were stable up to $196 \mathrm{degC}$. On further increase in temperature these ILs gradually decomposed in the temperature range of 197-258 degC. The variation was due to difference in constituted ion structure and interactive forces (Cao and $\mathrm{Mu}, 2014$; Golets et al., 2016). Especially imidazolium ions provide better stability due to compact ring structure and high inter molecular interactions (Maton et al., 2013). All the four ILs exhibited high thermal stability hence, these synthesized ILs are effective lubricant additives for base oil operating at high temperature.

\section{Antiwear Performance}

A series of wear tests was conducted to evaluate the antiwear behaviour of synthesized ILs in two different base oils EKE and DOS by varying the concentration (wt \%) of additives. Fig. 5 (a and b) illustrates the variation in wear scar diameter (WSD) with IL concentration. There observed decrease in WSD by increasing the concentration from 0.2 to $0.8 \mathrm{wt} \%$. At $0.8 \mathrm{wt} \%$ all the four synthesized ILs showed excellent antiwear performance in two base oils. Further increasing the additive concentration to 1.0 and $1.2 \mathrm{wt} \%$ no significant reduction in WSD was observed thus $0.8 \mathrm{wt} \%$ was taken as optimized additive concentration. Higher wear scar above the optimized concentration might be due to the adsorption of excess amount of additive on the metal surface, which leads to coagulation and causes severe damage to the tribofilm by increase in frictional force and results in excess wear on rubbing surface (Wang et al., 2013). Fig. 5 illustrates that all the synthesized ILs showed lower WSD in both base oils at all the concentrations. Exclusively, the additive BHI-RA exhibited maximum reduction in WSD of both base oils. WSD of base oil EKE reduced from 0.846 to $0.602 \mathrm{~mm}$ and in the case of DOS it is from 0.872 to $0.617 \mathrm{~mm}$. The presence of TBA-RA, TPA-RA, CTBRA and BHI-RA in base oil EKE significantly reduced the WSD by 17, 21, 25 and $28 \%$ respectively whereas, $38 \%$ reduction in WSD was observed with commercially available antiwear additive Lubrizol 1359. Overall, the order of antiwear behavior is as follows: BHI-RA > TBA-RA > TPA-RA > CTB-RA. Remarkable variation in antiwear behaviour among the four ILs indicates that the WSD is dependent on composition of IL. The antiwear behaviour of BHI-RA is slightly better than others which could be ascribed to the presence of heterocyclic imidazole ring. Variation in antiwar performance of TBA-RA and TPA-RA could be attributed to the alkyl chain length difference on quaternary ammonium ion. According to Gusain et al. (2017), longer alkyl chain containing quaternary ammonium ILs provide better lubrication performance than the shorter chains. Thus the IL TBA-RA showed better antiwear performance compared to TPA-RA.

The effect of applied load on WSD was also studied in order to estimate the performance of synthesized ILs at higher loads. The tests were conducted by varying the loads from 40 to $80 \mathrm{~kg}$ at optimized IL concentration $(0.8 \mathrm{wt} \%)$ and rotation speed $(1200 \mathrm{rpm})$ at 60 minutes run time and the results were presented in Fig. 6 . It clearly illustrates that at the initial load $(40 \mathrm{~kg})$ WSD of the two base oils is very high whereas, IL blended base oil exhibited lower WSD. Further increase in the load from 40 to $80 \mathrm{~kg}$ resulted increase in WSD but this increase is comparatively minimum to the neat base oil. This is may be due to decrease in the thickness of tribofilm between rubbing surfaces with increasing load (Yan et al., 2014). 
WSD as a function of the rotation speed was also studied at optimized additive concentration (0.8 wt\%) and load $40 \mathrm{~kg}$ at 60 minutes run time by varying the rotation speed from 1200 to $1742 \mathrm{rpm}$ and the results were presented in Fig. 7. The minimum WSD was observed with base oil and base oil blended additive at 1200 rpm meanwhile, raising the rotation speed from $1200 \mathrm{rpm}$ to $1742 \mathrm{rpm}$ increase in WSD was observed. This is due to break out of tribofilm caused by increasing entrainment force (Hu et al., 2013). Above experimental results indicate that the synthesized ILs are good tribo active additives to reduce the WSD of tested base oils even at higher load and rotation speed.

\section{Extreme Pressure Performance}

The extreme pressure (EP) behaviour of the synthesized ILs was analyzed in two base oils and the results were shown in Fig. 8. It can be seen that the weld point of two base oils improved with addition of synthesized ILs. The base oils EKE and DOS exhibited weld points 160 and $120 \mathrm{~kg}$ respectively, further the addition of ILs showed significant enhancement in weld points due to the development of effective tribofilm on the rubbing surface. Fig. 8 compares the weld points of base oils with different IL concentration from $0.25 \mathrm{wt} \%$ to $1.5 \mathrm{wt} \%$. While increasing the concentration from 0.25 to $1.25 \mathrm{wt} \%$ increase in weld point of the base oil was observed and further increasing the concentration to $1.5 \mathrm{wt} \%$ resulted in decrease of weld point, thus $1.25 \mathrm{wt} \%$ is taken as the optimized additive concentration. At this particular concentration all the synthesized additives were greatly effective in improving the weld point of the two base oils. The IL's BHI-RA, TBA-RA, TPA-RA and CTB-RA enhanced the weld point by $43,31,25$ and $25 \%$ respectively in base oil EKE. Exclusively, BHI-RA exhibited superior extreme pressure performance in both base oils. Yang et al. reported that the nitrogen containing heterocyclic compounds are capable to develop strong tribofilms under extreme pressure conditions (Yang et al., 2013). The weld points obtained with all the synthesized ILs were compared with commercially available additive dibenzyl disulfide (DBDS) and the results indicate that the synthesized ILs exhibited either comparable or better EP performance to DBDS.

\section{Surface Morphology}

SEM analysis was carried to study the surface morphology of steel balls after the wear tests. Fig. 9 (a and b) and Fig. 10 ( $a$ and b) shows the morphology of worn surface of steel balls lubricated by base oil EKE and EKE containing IL (BHI-RA), base oil DOS and DOS containing IL (BHI-RA) respectively. It can be observed that the base oil lubricated surface is quite rough with wide scratches and deep furrowed wear tracks which are signs of mordant wear. Whereas, the surface lubricated with base oil containing IL is smoother with few scratches and wear tracks which is in well accordance to the efficient antiwear behaviour of IL. These results show that a stable tribofilm formed with additive to prevent the direct contact between interacting surfaces (Ing et al., 2012). Fig. 11 (a and b) shows the EDX spectrum of worn surface lubricated with base oil EKE, DOS and base oil blended with BHI-RA (Fig. 11 (c and d)). It can be seen that the surface lubricated by neat base oil EKE and DOS shows iron, carbon and oxygen signals whereas, surface lubricated with IL blended base oil showed additional nitrogen signal. These findings further suggest that the incorporation of nitrogen on the surface provide the protection against severe wear damage.

\section{Conclusion}

Four novel ricinoleate anion-based ionic liquids were synthesized by metathesis of sodium ricinoleate with bromide salts and were evaluated as green lubricant additives in two base oils EKE and DOS. The synthesized additives exhibited excellent thermal stability and tribological performance. At optimal IL concentration the fatty acid constituted ILs greatly reduced the wear scar diameter and improved the weld point of both base oils. The results obtained from tribological tests confirmed that there is a significant effect of changing the cation on their tribological performance. The ionic liquids BHI-RA and TBA-RA exhibited better tribological performance compared to TPA-RA and CTB-RA under boundary lubrication conditions. Elemental mapping and worn surface morphology studies further confirmed the deposition of tribofilm by ricinoleate constituted ionic liquid. This study illustrates that fatty acid constituted ILs are excellent lubricating oil additives to minimize or replace the use of environmentally hazardous ILs.

\section{Supplementary Information (SI)}


This includes data for ${ }^{1} \mathrm{H},{ }^{13} \mathrm{C}$ NMR and FTIR spectra of synthesized ionic liquids

\section{References}

Amiril, S. A. S., Rahim, E. A., \& Syahrullail, S. (2017) A review on ionic liquids as sustainable lubricants in manufacturing and engineering: Recent research, performance and applications. Journal of Cleaner Production, 168: 1571-1589.

Barnhill, W. C., Qu, J., Luo, H., Meyer III, H. M., Ma, C., Chi, M., \& Papke, B. L. (2014) Phosphoniumorganophosphate ionic liquids as lubricant additives: effects of cation structure on physicochemical and tribological characteristics. ACS Applied Materials \& Interfaces , 6 :22585-22593.

Battez, A. H., Fernandes, C. M., Martins, R. C., Bartolome, M., Gonzalez, R., \& Seabra, J. H. (2017) Two phosphonium cation-based ionic liquids used as lubricant additive: Part I: Film thickness and friction characteristics. Tribology International , $107: 233-239$.

Battez, A. H., Blanc, D., Fernandez-Gonzalez, A., Mallada, M. T., \& Gonzalez Viesca, R. J. L. (2016) Friction, wear and tribofilm formation with a $\left[\mathrm{NTf}_{2}\right]$ anion-based ionic liquid as neat lubricant. Tribology International , 103 :73-86.

Cao, Y., \& Mu, T. (2014) Comprehensive investigation on the thermal stability of 66 ionic liquids by thermogravimetric analysis.Industrial \&3 Engineering Chemistry Research ,53 :8651-8664.

Drown, D. C., Harper, K., \& Frame, E. (2001) Screening vegetable oil alcohol esters as fuel lubricity enhancers. Journal of the American Oil Chemists' Society, 78 :579-584.

Golets, M., Shimpi, M. R., Wang, Y. L., Antzutkin, O. N., Glavatskih, S., \& Laaksonen, A. (2016) Understanding the thermal decomposition mechanism of a halogen-free chelated orthoborate-based ionic liquid: a combined computational and experimental study. Physical Chemistry Chemical Physics , 18 :22458-22466.

Gusain, R., Gupta, P., Saran, S., \& Khatri, O. P. (2014) Halogen-free bis (imidazolium)/bis (ammonium)di [bis (salicylato) borate] ionic liquids as energy-efficient and environmentally friendly lubricant additives. ACS Applied Materials \& Interfaces , 6 :15318-15328.

Gusain, R., \& Khatri, O. P. (2016) Fatty acid ionic liquids as environmentally friendly lubricants for low friction and wear. RSC Advances , 6 :3462-3469.

Gusain, R., Dhingra, S., \& Khatri, O. P. (2016) Fatty-acid-constituted halogen-free ionic liquids as renewable, environmentally friendly and high-performance lubricant additives. Industrial $\mathscr{E}$ Engineering Chemistry Research , 55 :856-865.

Gusain, R., Bakshi, P. S., Panda, S., Sharma, O. P., Gardas, R., \& Khatri, O. P. (2017) Physicochemical and tribophysical properties of trioctylalkylammonium bis (salicylato) borate (N888 n-BScB) ionic liquids: effect of alkyl chain length. Physical Chemistry Chemical Physics , 19 :6433-6442.

Hu, E., Hu, X., Liu, T., Fang, L., Dearn, K. D., \& Xu, H. (2013) The role of soot particles in the tribological behavior of engine lubricating oils. Wear , 304 :152-161.

Ichiro, M. (2009) Ionic liquids in tribology. Molecules ,14:2286-2305.

Ing, T. C., Rafiq, A. K. M., Azli, Y., \& Syahrullail, S. (2012) Tribological behaviour of refined bleached and deodorized palm olein in different loads using a four-ball tribotester. Scientia Iranica ,19:1487-1492.

Jimeenez, A. E., \& Bermudez, M. D. (2008) Imidazolium ionic liquids as additives of the synthetic ester propylene glycol dioleate in aluminium-steel lubrication. Wear , 265 :787-798.

Khan, A., Gusain, R., \& Khatri, O. P. (2018) Organophosphate anion based low viscosity ionic liquids as oil-miscible additives for lubrication enhancement. Journal of Molecular Liquids ,272:430-438. 
Khatri, P. K., Aathira, M. S., Thakre, G. D., \& Jain, S. L. (2018) Synthesis and tribological behavior of fatty acid constituted tetramethylguanidinium (TMG) ionic liquids for a steel/steel contact.Materials Science and Engineering: C , 91 :208-217.

Khemchandani, B., Somers, A., Howlett, P., Jaiswal, A. K., Sayanna, E., \& Forsyth, M. (2014) A biocompatible ionic liquid as an antiwear additive for biodegradable lubricants. Tribology International,77 $: 171-177$.

Kronberger, M., Pejakovic, V., Gabler, C., \& Kalin, M. (2012) How anion and cation species influence the tribology of a green lubricant based on ionic liquids. Proceedings of the Institution of Mechanical Engineers, Part J; Journal of engineering tribology, 226 : 933-951.

Liu, X., Zhou, F., Liang, Y., \& Liu, W. (2006) Tribological performance of phosphonium based ionic liquids for an aluminum-on-steel system and opinions on lubrication mechanism. Wear, 261 :1174-1179.

Ma, Y., Li, Z., Wang, H., \& Li, H. (2019) Synthesis and optimization of polyurethane microcapsules containing [BMIm] $\mathrm{PF}_{6}$ ionic liquid lubricant. Journal of Colloid and Interface Science, ,534 :469-479.

Madankar, C. S., Pradhan, S., \& Naik, S. N. (2013) Parametric study of reactive extraction of castor seed (Ricinus communis L.) for methyl ester production and its potential use as bio lubricant.Industrial Crops and Products , 43 :283-290.

Matczak, L., Johanning, C., Gil, E., Guo, H., Smith, T. W., Schertzer, M., \& Iglesias, P. (2018) Effect of cation nature on the lubricating and physicochemical properties of three ionic liquids. Tribology International , $124: 23-33$.

Maton, C., De, Vos, N., \& Stevens, C. V. (2013) Ionic liquid thermal stabilities: decomposition mechanisms and analysis tools. Chemical Society Reviews , 42 :5963-5977.

McFarlane, D. R., Sun, J., Golding, J., Meakin, P., \& Forsyth, M. (2000) High conductivity molten salts based on the imide ion.Electrochica Acta , 45 :1271-1278.

Mendonca, A. C., Malfreyt, P., \& Padua, A. A. (2012) Interactions and ordering of ionic liquids at a metal surface. Journal of Chemical Theory and Computation , 8 :3348-3355.

Minami, I., Inada, T., Sasaki, R., \& Nanao, H. (2010) Tribo-chemistry of phosphonium-derived ionic liquids. Tribology Letters , $40: 225-235$.

Mordukhovich, G., Qu, J., Howe, J. Y., Bair, S., Yu, B., Luo, H., Smolenski, D. J., Blau, P. J., Bunting, B. G., \& Dai, S. (2013) A low-viscosity ionic liquid demonstrating superior lubricating performance from mixed to boundary lubrication. Wear ,301:740-746.

Mu, Z., Wang, X., Zhang, S., Liang, Y., Bao, M., \& Liu, W. (2008) Investigation of tribological behavior of Al-Si alloy against steel lubricated with ionic liquids of 1-diethylphosphonyl-n-propyl-3-alkylimidazolium tetrafluoroborate.Journal of Tribology , $130: 034501$.

Mu, L., Shi, Y., Guo, X., Ji, T., Chen, L., Yuan, R., Brisbin, L., Wang, H., \& Zhu, J. (2015) Non-corrosive green lubricants: strengthened lignin-[choline][amino acid] ionic liquids interaction via reciprocal hydrogen bonding. RSC Advances, 5 :66067-66072.

Otero, I., Loopez, E. R., Reichelt, M., Villanueva, M., Salgado, J., \& Fernaandez, J. (2014) Ionic liquids based on phosphonium cations as neat lubricants or lubricant additives for a steel/steel contact. ACS Applied Materials \& Interfaces , 6 :13115-13128.

Oulego, P., Blanco, D., Ramos, D., Viesca, J. L., Diaz, M., \& Battez, A. H. (2018) Environmental properties of phosphonium, imidazolium and ammonium cation-based ionic liquids as potential lubricant additives. Journal of Molecular Liquids, 272 :937-947. 
Pejakovic, V., Tomastik, C., Dorr, N., \& Kalin, M. (2016) Influence of concentration and anion alkyl chain length on tribological properties of imidazolium sulfate ionic liquids as additives to glycerol in steel-steel contact lubrication. Tribology International ,97:234-243.

Pensado, A. S., Comunas, M. J. P., \& Fernandez, J. (2008) The pressure-viscosity coefficient of several ionic liquids. Tribology Letters, $\mathbf{3 1}: 107-118$.

Qu, J., Truhan, J. J., Dai, S., Luo, H., \& Blau, P. J. (2006) Ionic liquids with ammonium cations as lubricants or additives. Tribology Letters, 22 :207-214.

Qu, J., Bansal, D. G., Yu, B., Howe, J. Y., Luo, H., Dai, S., Li, H., Blau, P. J., Bunting, B. G., Mordukhovich, G., \& Smolenski, D. J. (2012) Antiwear performance and mechanism of an oil-miscible ionic liquid as a lubricant additive. ACS Applied Materials \& Interfaces , $4: 997-1002$.

Qu, J., Barnhill, W. C., Luo, H., Meyer III, H. M., Leonard, D. N., Landauer, A. K., Kheireddin, B., Gao, H., Papke, B. L., \& Dai, S. (2015) Synergistic effects between phosphonium-alkylphosphate ionic liquids and zinc dialkyldithiophosphate (ZDDP) as lubricant additives.Advanced Materials , 27 :4767-4774.

Salih, N., Salimon, J., \& Yousif, E. (2011) The physicochemical and tribological properties of oleic acid based triester biolubricants.Industrial Crops and Products , 34 :1089-1096.

Somers, A. E., Howlett, P. C., MacFarlane, D. R., \& Forsyth, M. (2013) A review of ionic liquid lubricants. Lubricants , 1 :3-21.

Somers, A. E., Biddulph, S. M., Howlett, P. C., Sun, J., MacFarlane, D. R., \& Forsyth, M. (2012) A comparison of phosphorus and fluorine containing IL lubricants for steel on aluminium. Physical Chemistry Chemical Physics, 14 :8224-8231.

Stolte, S., Steudte, S., Areitioaurtena, O., Pagano, F., Thoming, J., Stepnowski, P., \& Igartua, A. (2012) Ionic liquids as lubricants or lubrication additives: an ecotoxicity and biodegradability assessment. Chemosphere, 89 :1135-1141.

Swatloski, R. P., Holbrey, J. D., \& Rogers, R. D. (2003) Ionic liquids are not always green: hydrolysis of 1-butyl-3-methylimidazolium hexafluorophosphate. Green Chem istry, 5 :361-363.

Tiago, G., Restolho, J., Forte, A., Colaco, R., Branco, L. C., \& Saramago, B. (2015) Novel ionic liquids for interfacial and tribological applications. Colloids Surfaces A: Physicochemical and Engineering Aspects , $472: 1-8$.

Wang, S., Yue, W., Fu, Z. Q., Wang, C. B., Li, X. L., \& Liu, J. J. (2013) Study on the tribological properties of plasma nitrided bearing steel under lubrication with borate ester additive. Tribology International, 66 $: 259-264$.

Yang, G., Zhang, J., Zhang, S., Yu, L., Zhang, P., \& Zhu, B. (2013) Preparation of triazine derivatives and evaluation of their tribological properties as lubricant additives in poly-alpha olefin. Tribology International , $62: 163-170$.

Yan, J. C., Zeng, X. Q., van der Heide, E., Ren, T. H., \& Zhao, Y. D. (2014) The tribological behaviour and tribochemical study of B-N type borate esters in rapeseed oil-compound versus salt. RSC Advances ,4 :20940-20947.

Ye, C., Liu, W., Chen, Y., \& Yu, L. (2001) Room-temperature ionic liquids: a novel versatile lubricant. Chemical Communications ,21 :2244-2245.

Yu, B., Zhou, F., Pang, C., Wang, B., Liang, Y., \& Liu, W. (2008) Tribological evaluation of $\alpha$, $\omega-$ diimidazoliumalkylene hexafluorophosphate ionic liquid and benzotriazole as additive. Tribology International , $41: 797-801$. 
Zhang, Y., Cai, T., Shang, W., Sun, L., Liu, D., Tong, D., \& Liu, S. (2017) Environmental friendly polyisobutylene-based ionic liquid containing chelated orthoborate as lubricant additive: Synthesis, tribological properties and synergistic interactions with ZDDP in hydrocarbon oils. Tribology International , 115 :297-306.

Zhou, F., Liang, Y., \& Liu, W. (2009) Ionic liquid lubricants: designed chemistry for engineering applications. Chemical Society Reviews, 38 :2590-2599.

Zhou, Y., Dyck, J., Graham, T. W., Luo, H., Leonard, D. N., \& Qu, J. (2014) Ionic liquids composed of phosphonium cations and organophosphate, carboxylate, and sulfonate anions as lubricant antiwear additives. Langmuir , 30 :13301-13311.

Figure Captions

Fig. 1 Chemical structures of synthesized ionic liquids

Fig. 2 FT-IR spectra of synthesized ionic liquids

Fig. 3 Differential scanning calorimetric thermo grams of (a) CTB-RA and (b) BHI-RA

Fig. 4 TGA curves of ionic liquids under nitrogen atmosphere

Fig. 5 Variation of wear scar diameter with different concentrations of additives in base oil (a) EKE and (b) DOS

Fig. 6 Variation of wear scar diameter with different loads of additives in base oil (a) EKE and (b) DOS

Fig. 7 Variation of wear scar diameter with different rotation speed (rpm) of additives in base oil (a) EKE and (b) DOS

Fig. 8 Weld points at different concentration of additives in base oil EKE and DOS

Fig. 9 SEM images of the worn surface lubricated with (a) EKE and (b) EKE containing $0.8 \%$ of BHI-RA

Fig. 10 SEM images of the worn surface lubricated with (a) DOS and (b) DOS containing $0.8 \%$ of BHI-RA

Fig. 11 EDS analysis of the worn surfaces lubricated with (a) EKE, (b) DOS, (c) EKE containing 0.8\% of BHI-RA and (d) DOS containing $0.8 \%$ of BHI-RA

\section{Hosted file}

Figures.docx available at https://authorea.com/users/299391/articles/428812-synthesis-ofricinoleate-anion-based-ionic-liquids-and-their-application-as-green-lubricating-oiladditives

\section{Hosted file}

Table.docx available at https://authorea.com/users/299391/articles/428812-synthesis-ofricinoleate-anion-based-ionic-liquids-and-their-application-as-green-lubricating-oiladditives 